\title{
Is amputation in the elderly patient with critical limb ischemia acceptable in the long term?
}

This article was published in the following Dove Press journal:

Clinical Interventions in Aging

\author{
Chloé ML Peters \\ Jolanda de Vries ${ }^{2,3}$ \\ Eelco J Veen' \\ Hans GW de Groot' \\ Gwan $\mathrm{H} \mathrm{Ho}$ \\ Paul Lodder ${ }^{2,4}$ \\ Stijn L Steunenberg' \\ Lijckle van der Laan' \\ 'Department of Surgery, Amphia \\ Hospital, Breda, The Netherlands; \\ ${ }^{2}$ Department of Medical and Clinical \\ Psychology, Tilburg University, Tilburg, \\ The Netherlands; ${ }^{3}$ Department of \\ Medical Psychology, Elisabeth- \\ Tweesteden Hospital (ETZ), Tilburg, The \\ Netherlands; ${ }^{4}$ Department of \\ Methodology and Statistics, Tilburg \\ University, Tilburg, The Netherlands
}

Correspondence: Chloé ML Peters Department of Surgery, Amphia Hospital, Molengracht 2I, 48I8 CK, Breda, The Netherlands

Tel +3I 765955000

$\mathrm{Fax}+31765953818$

Email cpetersI@amphia.nl
Purpose: Despite high amputation rates, data on patient-reported outcomes is scarce in the elderly population with critical limb ischemia. The aim of this study was to provide mortality rates and long-term changes of the following patient-reported outcomes in elderly critical limb ischemia amputees: quality of life (QoL), health status (HS), and symptoms of depression.

Patients and methods: In this prospective observational cohort study, amputated critical limb ischemia patients $\geq 70$ years were included. The follow-up period was two years. Within the follow-up period patients completed the following questionnaires: the World Health Organization Quality Of Life -abbreviated version of the WHOQOL 100 (WHOQOLBREF), the 12-Item Short Form Health Survey, and the Center for Epidemiological Studies Depression Scale.

Results : A total of 49 elderly patients with critical limb ischemia had undergone major limb amputation within two years after inclusion. In these patients, the one-year mortality rate was $39 \%$ and the two-year mortality rate was $55 \%$. The physical QoL was the only domain of the WHOQOL-BREF that improved significantly across time after amputation $(p \leq 0.001)$. In the long-term, there was no difference in the ability to enjoy life $(\mathrm{p}=0.380)$ or the satisfaction in performing daily living activities $(p=0.231)$ compared to the scores of the general elderly population. After amputation, the physical HS domain $(\mathrm{p} \leq 0.001)$ and the mental HS domain $(p=0.002)$ improved. In the first year, amputees experienced less symptoms of depression $(\mathrm{p}=0.004)$.

Conclusion: Elderly critical limb ischemia amputees are a fragile population with high mortality rates. Their QoL and HS increased after major limb amputation as compared to the baseline situation and they experienced less symptoms of depression. Moreover, our results show that, in the long-term, major limb amputation in the elderly patients with critical limb ischemia shows an acceptable QoL, which, in some aspects, is comparable to the QoL of their peers. These results can improve the shared-decision making process that does not delay the timing of major limb amputation.

Keywords: amputation, critical limb ischemia, frail elderly, health status, quality of life

\section{Introduction}

Critical limb ischemia is the most severe stage of peripheral arterial disease (PAD) and is characterized by ischemic rest pain and/or tissue loss. In patients with critical limb ischemia, the main goal of treatment is to salvage the affected limb. ${ }^{1,2}$ The success of treatment for critical limb ischemia is measured by amputation free survival (AFS). ${ }^{2}$ In order to achieve this desired outcome, patients with critical limb ischemia are aggressively revascularized by endovascular or surgical procedures, if possible. ${ }^{1,2}$ However, despite these efforts, amputation rates remain high. One year 
after the onset of critical limb ischemia, $25 \%$ of patients will have to undergo a major limb amputation ${ }^{2,3}$ and approximately $35-67 \%$ of critical limb ischemia patients undergoes major limb amputation within four years. ${ }^{4}$ Moreover, early post-operative mortality rates range from $4 \%$ to $22 \%$ after major limb amputation from any cause. ${ }^{5}$ Early mortality rates of up to $20 \%$ are reported in critical limb ischemia amputees. 6,7

Because of high amputation and mortality rates functional status and mobility success have been studied. ${ }^{8,9}$ Norvell et al and Taylor et al report that successful outcome is associated with mobility capacity. ${ }^{8,9}$ However, mobility is often impaired in elderly patients with critical limb ischemia. This raises the question whether an assessment of objective functioning, which is expected to be impaired, can be considered a good patient-reported outcome of treatment success. Other patient-reported outcomes (PROs), such as quality of life (QoL) and health status (HS), are increasingly relevant in critical limb ischemia patients. ${ }^{10-12}$ QoL and HS are supplementary, in the sense that HS questionnaires, like the SF-12, focus on physical, psychological, and social objective functioning and QoL questionnaires measure the patients' own satisfaction or evaluation of functioning. ${ }^{11,13,14}$

Furthermore, little is known about the QoL and HS of critical limb ischemia amputees. ${ }^{15}$ The lack of literature on long-term results is due to high mortality rates. Besides, the absolute number of amputees per hospital is low. Additionally, reports on changes in other mental health disorders, like depression, after major limb amputation for critical limb ischemia patients, is lacking in literature. ${ }^{16}$

Therefore, the aim of this prospective observational cohort study was to provide short-term and long-term changes of the following patient-reported outcomes in elderly critical limb ischemia amputee patients: QoL, HS, and symptoms of depression. The scores of specified World Health Organization Quality Of Life -abbreviated version of the WHOQOL 100 (WHOQOL-BREF) questions of the elderly sample in the current study were compared to the normal scores in the general elderly population. In addition, the thirty-days, six-month, one-year and two-year mortality rates of elderly critical limb ischemia patients after major limb amputation will be addressed.

\section{Methods}

In this prospective observational cohort study, patients with critical limb ischemia aged 70 years and older undergoing a major limb amputation, were included between January 2012 and February 2016. ${ }^{17}$ Exclusion criteria were a diagnosis of malignancy, lack of Dutch language skills, or cognitive impairment. This study was conducted in accordance with the Declaration of Helsinki. Based on the criteria of the Central Committee on Research Involving Human Subjects, a formal written waiver for ethical approval was not required. The institutional medical ethical committee (AMOA) approved this. All patients included signed an informed consent.

At a weekly multidisciplinary vascular conference, a panel of experts placed the patients into one of four treatment groups: surgical revascularisation, endovascular revascularisation, conservative therapy, or major limb amputation. During follow-up, secondary major limb amputation was recorded. The follow-up period was two years after inclusion.

Within this follow-up period patients completed the following self-report questionnaires at six specified times: WHOQOL-BREF, the 12-Item Short Form Health Survey (SF-12), and the Center for Epidemiological Studies Depression Scale (CES-D). Patients who underwent major limb amputation during the 2-year follow-up period were selected for this study. Questionnaires were gathered that were completed six months, one year, and between one-and-a-half years and two years after major limb amputation.

\section{WHOQOL-BREF}

In the elderly, the validated WHOQOL-BREF questionnaire was utilized to measure QoL. ${ }^{18,19}$ This patient-completed measurement of health-related QoL is the short version of the WHOQOL-100 and contains 26 items with a 5-point Likert type response scale. These 26 questions are grouped into four domains (physical health, psychological health, social relationships, and environment) and a general QoL facet. The WHOQOL-BREF is reliable and valid instrument for measuring quality of life in the Dutch adult population. ${ }^{10,18,20}$

\section{SF-I 2}

The SF-12 is a reliable and valid instrument for measuring HS of the elderly population. ${ }^{21}$ The SF-12 is a shortened version of the RAND 36-Item Short Form Health Survey. ${ }^{22}$ The questionnaire consists of 12 questions with three to five response levels, which are completed by patients. It determines HS, which can be divided into the Physical Component Summary (PCS) scale and the Mental Component Summary (MCS) scale. ${ }^{10,22,23}$ 


\section{CES-D}

Symptoms of depression were measured by means of the CES-D questionnaire. ${ }^{24,25}$ In this study, the abbreviated 16-item version was applied, which is both widely used and easy in use, especially in the elderly population. ${ }^{25} \mathrm{In}$ this questionnaire, patients were presented with 16 symptoms of depression and asked if they experienced any of them. If they had experienced any of the sixteen symptoms, the frequency and duration within the past week was asked to be noted. A CES-D cut off score of $\geq 12$ specified patients with symptoms of depression. ${ }^{26}$

\section{Statistical analysis}

Statistical analyses were done using a computerized software package: SPSS version 23 (IBM, Chicago IL, USA). Continuous and normally distributed variables were expressed in terms of means and standard deviations. Continuous and non-normally distributed variables were expressed in terms of medians and interquartile ranges. The Shapiro-Wilk test was used to assess whether continuous variables were normally distributed. Categorical variables were expressed in terms of frequencies and percentages. Item-level missing data was imputed according to the guidelines of the particular questionnaire. Scale-level missing data was directly handled through maximum likelihood estimation, as implemented in the mixed modeling procedure. Linear mixed models were used to assess the change of QoL, HS, and symptoms of depression at three specified times. Within mixed modeling, custom hypothesis tests were used to assess differences between baseline and follow-up measurements. Lastly, one sample $t$-tests were used to compare the mean QoL estimates to corresponding estimates in the general elderly population. ${ }^{27} \mathrm{~A} p$-value of less than 0.05 was considered significant.

\section{Results}

A total of 387 patients of 70 years or older were diagnosed with critical limb ischemia during the inclusion period of which 388 patients were excluded based on the criteria previously stated. Two years after inclusion in this study, a total of 49 elderly critical limb ischemia patients had undergone major limb amputation of the affected limb. These patients were selected from a cohort initially treated with surgical revascularisation $(\mathrm{n}=12)$, endovascular revascularisation $(n=21)$, conservative therapy $(n=11)$, or primary major limb amputation $(n=5)$. In Table 1 , the patient characteristics of all amputees are presented.
Table I Patient characteristics

\begin{tabular}{|c|c|}
\hline & $\begin{array}{l}\text { Amputees } \\
n=49(100 \%)\end{array}$ \\
\hline Sex (male) & $31(64)$ \\
\hline Median Age (IQR) & $82(75 ; 84)$ \\
\hline \multicolumn{2}{|l|}{ Living situation } \\
\hline - Independent* & $23(47)$ \\
\hline - Home care & $17(35)$ \\
\hline - Nursing facility & $6(12)$ \\
\hline - Missing & $3(6)$ \\
\hline \multicolumn{2}{|l|}{ Civil status } \\
\hline - Single & $8(16)$ \\
\hline - Married or living with partner* & $22(45)$ \\
\hline - Divorced & $2(4)$ \\
\hline - Widowed* & $14(29)$ \\
\hline - Missing & $3(6)$ \\
\hline \multicolumn{2}{|l|}{ Educational level } \\
\hline - Low & $20(4 I)$ \\
\hline - Middle & $20(4 I)$ \\
\hline - High & $6(12)$ \\
\hline - Missing & $3(6)$ \\
\hline Currently smoking & $10(20)$ \\
\hline Cardiac comorbidity & $4 \mathrm{I}(84)$ \\
\hline Neurologic comorbidity & $17(35)$ \\
\hline Pulmonary comorbidity & $36(74)$ \\
\hline Renal impairment & $29(59)$ \\
\hline Arthrosis & $9(18)$ \\
\hline Diabetes mellitus & $27(55)$ \\
\hline Hypertension & $31(63)$ \\
\hline \multicolumn{2}{|l|}{ Rutherford classification* } \\
\hline - Rutherford-class 4 & $8(16)$ \\
\hline - Rutherford-class $5 / 6$ & $4 I(84)$ \\
\hline \multicolumn{2}{|l|}{ ASA classification } \\
\hline - ASA 2 & $9(19)$ \\
\hline - ASA 3 & $35(7 I)$ \\
\hline- ASA 4 & $5(10)$ \\
\hline \multicolumn{2}{|l|}{ Initially selected therapy } \\
\hline - Endovascular revascularization & $21(43)$ \\
\hline - Surgical revascularization & $12(24)$ \\
\hline - Conservative therapy & II (23) \\
\hline - Primary amputation & $5(10)$ \\
\hline Previous minor amputation & $13(27)$ \\
\hline \multicolumn{2}{|l|}{ Type of amputation } \\
\hline - Above knee amputation & $15(31)$ \\
\hline - Through knee amputation & $4(8)$ \\
\hline - Below knee amputation & $30(6 \mathrm{I})$ \\
\hline
\end{tabular}

Notes: Data are presented as $n(\%)$, unless otherwise specified. *Significant difference between age groups $(p<0.05)$.

Abbreviations: $n$, number of patients; IQR, interquartile range; ASA, American Society of Anesthesiologists. 


\section{Clinical outcome \& mortality}

Place of discharge is shown in Table 2. A small proportion of patients $(n=9,18 \%)$ were able to go home after major limb amputation. To the best of our knowledge, 17 amputees $(35 \%)$ used a prosthesis at some point after major limb amputation. The thirty-day mortality rate was $16 \%$. After 6 months, 31\% of the amputees had deceased. The one-year mortality rate was $39 \%$ and the two-year mortality rate increased to $55 \%$.

\section{Patient-reported outcome}

Table 3 gives an overview of the median time between amputation and the conduction of the CES-D, the WHOQOL-BREF and the SF-12. As presented in Table 4, the physical QoL was the only domain of the WHOQOLBREF that significantly improved in time, after amputation. This improvement occurred at the 6-month measurement compared with the baseline measurement (11.29 vs 14.44 ; $p \leq 0.001,95 \%$ CI $1.61 ; 4.29)$ and remained significant after $1.5-2$ years ( 11.29 vs $14.75 ; p \leq 0.001,95 \%$ CI $2.49 ; 4.96)$. There were no significant differences in time for the overall, psychological, environmental, and social domains of the WHOQOL-BREF. The SF-12 also showed improvement in their physical HS domain, after 6 months compared with the baseline measurement ( 29.73 vs $34.97 ; p=0.015$, $95 \%$ CI $0.91 ; 7.82)$. This improvement remained significant after 1.5-2 years compared with the baseline measurement (29.73 vs $35.72 ; p \leq 0.001,95 \%$ CI $3.02 ; 9.10)$. The mental

Table 2 Patient discharge

\begin{tabular}{|l|l|}
\hline & $\begin{array}{l}\text { Amputees } \\
\mathbf{n = 4 9} \text { (100\%) }\end{array}$ \\
\hline Discharge to & \\
- Home & $9(18)$ \\
- Nursing facility & $16(33)$ \\
- Inpatient rehabilitation & $18(37)$ \\
- Decease before discharge & $3(6)$ \\
- Missing & $3(6)$ \\
\hline
\end{tabular}

Notes: Data are presented as $\mathrm{n}$ and (\%).

Table 3 Time to conduction of the questionnaires

\begin{tabular}{|l|l|l|l|}
\hline & n & Median time & IQR \\
\hline Baseline & 49 & & \\
Half year & 23 & 167 & $148-185$ \\
I year & 16 & 357 & $336.5-362.75$ \\
I.5-2 years & 11 & 697 & $65 I-726$ \\
\hline
\end{tabular}

Note: Data presented as median.

Abbreviations: $n$, number of patients; IQR, interquartile range.
HS domain only showed a significant improvement after 1.5-2 years compared with the baseline measurement (38.64 vs $44.46 ; p=0.002,95 \%$ CI $3.88 ; 12.59$ ). Amputee patients experienced less symptoms of depression after 6 months (8.69 vs $4.45 ; p=0.004,95 \%$ CI $-5.91 ;-1.22)$ and after 12 months (8.69 vs 4.56 ; $p=0.004,95 \%$ CI -6.62 ; $-1.40)$, compared with their baseline measurement.

Table 5 compares the scores of specified WHOQOLBREF questions at baseline and after amputation to normal scores in the general elderly population. ${ }^{27}$ While at baseline the current elderly sample showed significantly higher pain scores than the general elderly population (mean $\Delta=0.769 ; p<0.001 ; 95 \%$ CI $0.47 ; 1.06$ ), the pain scores significantly improved and reached a level significantly lower than the normal values of the elderly, both in the short-term (mean $\Delta=-0.603 ; p=0.022 ; 95 \%$ CI -1.11 ; -0.10 ) and in the long-term (mean $\Delta=-0.824 ; p=0.024$; $95 \%$ CI $-1.51 ;-0.13)$. Elderly critical limb ischemia amputees were able to accept their bodily appearance less, compared to the corresponding elderly. However, their scores did not differ from their pre-amputation scores. Overall, amputees rated their own quality of life significantly lower than the corresponding elderly in the long-term (mean $\Delta=-0.605 ; p=0.003$, 95\% CI -0.96 ; $-0.25)$. However in the long-term, there was no difference in the ability to enjoy life (mean $\Delta=0.145 ; p=0.380$; $95 \%$ CI $-0.21 ; 0.50)$, the amount of energy the elderly had (mean $\Delta=-0.545 ; p=0.052 ; 95 \%$ CI $-1.10 ; 0.01$ ), or the satisfaction in performing daily living activities (mean $\Delta=-0.265 ; p=0.231 ; 95 \%$ CI $-0.73 ; 0.20$ ).

\section{Discussion}

PROs have become a very important outcome of treatment in the elderly critical limb ischemia patients. ${ }^{10-12}$ Considering that a quarter of critical limb ischemia patients undergo major limb amputation during the first year after disease onset, there is a surprising lack of PROs in the vascular amputees. ${ }^{15}$ Compared to other multicenter studies, we assessed a relatively large number of critical limb ischemia amputee patients, aged 70 and older, on PROs and clinical outcomes in a prospective observational cohort two-center study. A selection of questions from the WHOQOL-BREF questionnaire, relevant for amputees, was compared to the corresponding values of their elderly peers. $^{27}$

The main finding was that physical QoL and physical HS significantly improved after amputation in elderly critical limb ischemia patients. Mental HS also improved but 
Table 4 Patient-reported outcomes for amputees $(n=49)$

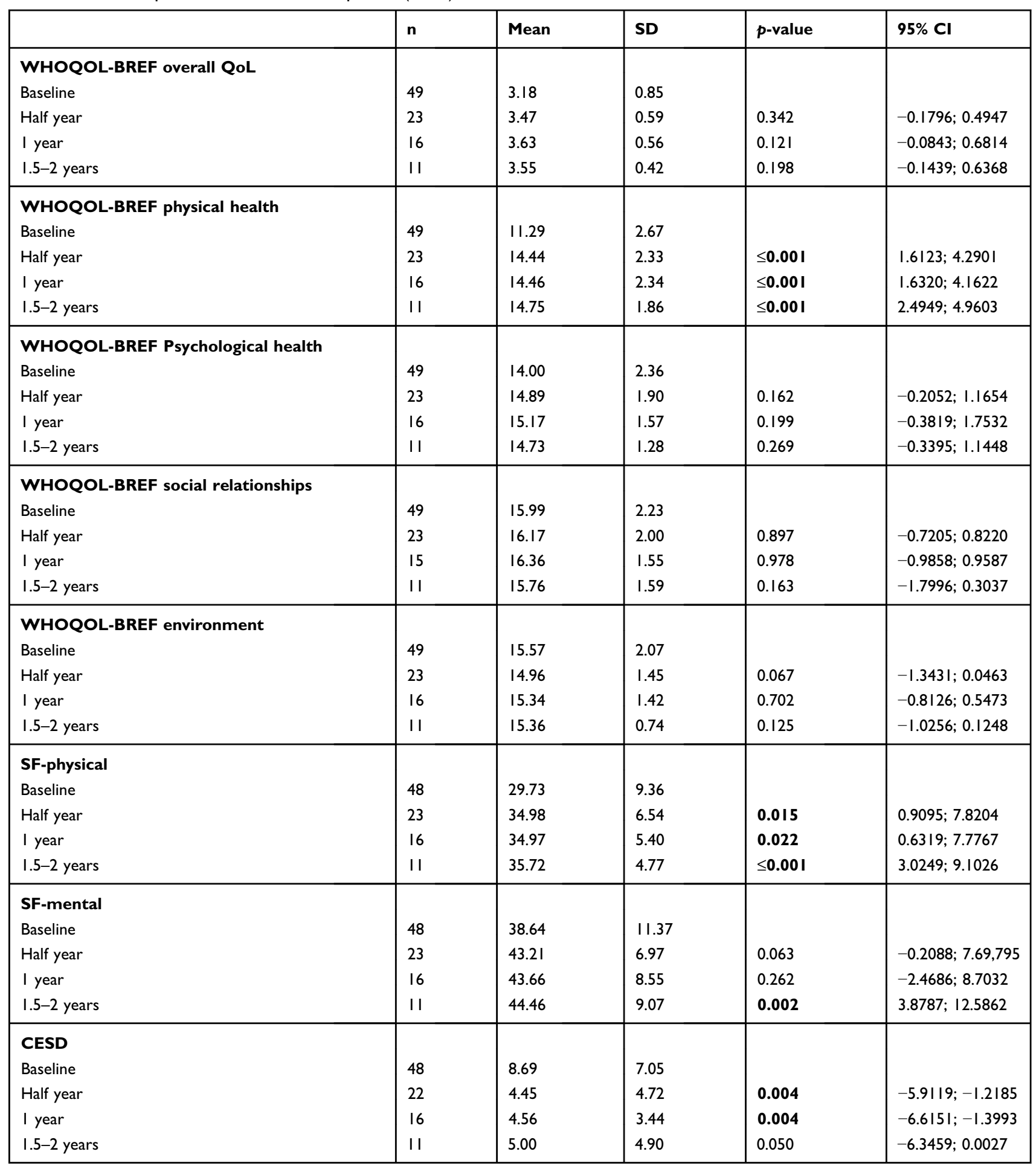

Notes: Data presented as mean. A p-value $<0.05$ is considered significant and is characterized by bold text.

Abbreviations: $n$, number of patients; SD, standard deviation; $\mathrm{Cl}$, confidence interval; WHOQOL-BREF, World Health Organization Quality Of Life -abbreviated version of the WHOQOL 100; CESD, Center for Epidemiologic Studies Depression.

only in the long-term. This study also demonstrated that critical limb ischemia patients experienced less symptoms of depression after amputation compared to baseline. Mortality rates were also analysed. The one-year mortality rate was $39 \%$ and two-year was $55 \%$.
Reduced physical functioning and QoL characterize critical limb ischemia patients. ${ }^{2}$ Therefore, one of the goals of the treatment of critical limb ischemia is to improve their physical function and QoL. ${ }^{2,28}$ Primary major limb amputation, without an attempt at 
Table 5 WHOQOL-BREF compared to normal values for elderly

\begin{tabular}{|c|c|c|c|c|c|c|}
\hline & $\mathbf{n}$ & Value & Value of general elderly population ${ }^{27}$ & Mean difference & p-value & $95 \% \mathrm{Cl}$ \\
\hline \multicolumn{7}{|c|}{ Item I. How would you rate your quality of life? } \\
\hline \multicolumn{7}{|c|}{ Very poor (I) - poor (2) - neither poor nor good (3) - good (4) - very good (5) } \\
\hline Baseline & 49 & 3.33 & 4.06 & -0.733 & $<0.001$ & $-1.01 ;-0.46$ \\
\hline Half year & 22 & 3.27 & & -0.787 & $<0.001$ & $-1.10 ;-0.48$ \\
\hline I year & 17 & 3.65 & & -0.413 & 0.027 & $-0.77 ;-0.05$ \\
\hline I.5-2 years & 11 & 3.45 & & -0.605 & 0.003 & $-0.96 ;-0.25$ \\
\hline
\end{tabular}

Item 3. To what extend do you feel that physical pain prevents you from doing what you need to do?

Not at all (I) - a little (2) - a moderate amount (3) - very much (4) - an extreme amount (5)

\begin{tabular}{|l|l|l|l|l|l|l|}
\hline Baseline & 48 & 3.23 & $\mathbf{2 . 4 6}$ & 0.769 & $<0.001$ & $0.47 ; 1.06$ \\
Half year & 21 & 1.86 & & -0.603 & $\mathbf{0 . 0 2 2}$ & $-1.11 ;-0.10$ \\
I year & 16 & 1.56 & & -0.898 & $\mathbf{0 . 0 0 2}$ & $-1.41 ;-0.38$ \\
I.5-2 years & $1 \mathrm{I}$ & 1.64 & & -0.824 & $\mathbf{0 . 0 2 4}$ & $-1.5 \mathrm{I} ;-0.13$ \\
\hline
\end{tabular}

Item 5. How much do you enjoy life?

Not at all (I) - a little (2) - a moderate amount (3) - very much (4) - an extreme amount (5)

\begin{tabular}{|l|l|l|l|l|l|l|}
\hline Baseline & 49 & 3.10 & 3.31 & -0.208 & 0.083 & $-0.44 ; 0.03$ \\
Half year & 22 & 3.48 & & 0.166 & 0.360 & $-0.20 ; 0.54$ \\
I year & 17 & 3.35 & & 0.043 & 0.852 & $-0.44 ; 0.52$ \\
I.5-2 years & 11 & 3.45 & & 0.145 & 0.380 & $-0.21 ; 0.50$ \\
\hline
\end{tabular}

Item 10. Do you have enough energy for everyday life?

Not at all (I) - a little (2) - moderately (3) - mostly (4) - completely (5)

\begin{tabular}{|c|c|c|c|c|c|c|}
\hline $\begin{array}{l}\text { Baseline } \\
\text { Half year } \\
\text { I year } \\
\text { I.5-2 years }\end{array}$ & $\begin{array}{l}49 \\
22 \\
17 \\
11\end{array}$ & $\begin{array}{l}3.29 \\
3.64 \\
3.41 \\
3.55\end{array}$ & 4.09 & $\begin{array}{l}-0.804 \\
-0.454 \\
-0.678 \\
-0.545\end{array}$ & $\begin{array}{l}<0.001 \\
<0.001 \\
<0.001 \\
0.052\end{array}$ & $\begin{array}{l}-1.10 ;-0.51 \\
-0.67 ;-0.24 \\
-1.00 ;-0.36 \\
-1.10 ; 0.01\end{array}$ \\
\hline \multicolumn{7}{|c|}{$\begin{array}{l}\text { Item I I. Are you able to accept you bodily appearance? } \\
\text { Not at all (I) - a little (2) - moderately (3) - mostly (4) - completely (5) }\end{array}$} \\
\hline $\begin{array}{l}\text { Baseline } \\
\text { Half year } \\
\text { I year } \\
\text { 1.5-2 years }\end{array}$ & $\begin{array}{l}48 \\
22 \\
17 \\
11\end{array}$ & $\begin{array}{l}3.77 \\
3.86 \\
3.88 \\
3.73\end{array}$ & 4.36 & $\begin{array}{l}-0.589 \\
-0.496 \\
-0.478 \\
-0.633\end{array}$ & $\begin{array}{l}<0.001 \\
0.007 \\
<0.001 \\
0.024\end{array}$ & $\begin{array}{l}-0.89 ;-0.29 \\
-0.84 ;-0.15 \\
-0.65 ;-0.31 \\
-1.16 ;-0.10\end{array}$ \\
\hline
\end{tabular}

Item 16. How satisfied are you with your ability to perform daily living activities?

Very dissatisfied (I) - dissatisfied (2) - neither satisfied nor dissatisfied (3) - satisfied (4) - very satisfied (5)

\begin{tabular}{|l|l|l|l|l|l|l|}
\hline Baseline & 49 & 2.88 & 3.81 & -0.932 & $<0.001$ & $-1.24 ;-0.63$ \\
Half year & 22 & 3.18 & & -0.628 & 0.006 & $-1.05 ;-0.20$ \\
I year & 17 & 3.24 & & -0.575 & $\mathbf{0 . 0 1 8}$ & $-1.04 ;-0.11$ \\
I.5-2 years & $1 \mathrm{I}$ & 3.55 & & -0.265 & $0.23 \mathrm{I}$ & $-0.73 ; 0.20$ \\
\hline
\end{tabular}

Item 18. How satisfied are you with yourself?

Very dissatisfied (I) - dissatisfied (2) - neither satisfied nor dissatisfied (3) - satisfied (4) - very satisfied (5)

\begin{tabular}{|l|l|l|l|l|l|l|}
\hline Baseline & 49 & 3.57 & 3.97 & -0.399 & $\mathbf{0 . 0 0 2}$ & $-0.65 ;-0.15$ \\
Half year & 22 & 3.82 & & -0.152 & 0.240 & $-0.41 ; 0.11$ \\
I year & 17 & 3.82 & & -0.146 & 0.270 & $-0.42 ; 0.13$ \\
I.5-2 years & 11 & 3.73 & & -0.243 & 0.116 & $-0.56 ; 0.07$ \\
\hline
\end{tabular}

(Continued) 
Table 5 (Continued).

\begin{tabular}{|c|c|c|c|c|c|c|}
\hline & $\mathbf{n}$ & Value & Value of general elderly population ${ }^{27}$ & Mean difference & $p$-value & $95 \% \mathrm{Cl}$ \\
\hline \multicolumn{7}{|c|}{ Item 25. How well are you able to get around? } \\
\hline \multicolumn{7}{|c|}{ Very poor (I) - poor (2) - neither poor nor good (3) - good (4) - very good (5) } \\
\hline Baseline & 47 & 2.49 & 3.70 & -1.211 & $<0.001$ & $-1.56 ;-0.87$ \\
\hline Half year & 22 & 3.32 & & -0.382 & 0.058 & $-0.78 ; 0.01$ \\
\hline I year & 17 & 3.53 & & -0.171 & 0.433 & $-0.62 ; 0.28$ \\
\hline I.5-2 years & 11 & 3.36 & & -0.366 & 0.255 & $-0.96 ; 0.28$ \\
\hline
\end{tabular}

Notes: Data presented as mean; The value of the general elderly population is based on reference 27. One sample $t$-tests were used to compare the mean QoL estimates to corresponding estimates in the general elderly population. A p-value of $<0.05$ is considered significant and is characterized by bold text.

Abbreviations: $\mathrm{n}$, number of patients; $\mathrm{Cl}$, confidence interval; QoL, quality of life; WHOQOL-BREF, World Health Organization Quality Of Life -abbreviated version of the WHOQOL 100 .

revascularization, is not often performed because we believe that these treatment goals cannot be achieved with major limb amputation. Still, a large proportion of critical limb ischemia patients must undergo secondary major limb amputation at some point in the course of their disease because of inadequate perfusion. Our cohort shows that improved physical QoL and physical HS are possible in the long-term. Moreover, the ability to enjoy life, the amount of energy elderly patients had, and/or the satisfaction in performing daily living activities is comparable to that of the Dutch elderly. Understandably, critical limb ischemia amputee patients report less pain symptoms than their peers. Still, these patients rate a poorer QoL and poorer acceptance of bodily appearance in these specific questions of the WHOQOL-BREF questionnaire. However, their scores of the acceptance of bodily appearance did not differ from their pre-amputation scores. In terms of personalized medicine and shared-decision making, it is important to understand the changes in the several domains of the questionnaires in comparison with the normal elderly population.

Suckow et al stated that QoL assessment in critical limb ischemia patients should incorporate patient preference ${ }^{15}$ In this study, the WHOQOL-BREF questionnaire was used. Though a consensus still has to be reached on a specific QoL measure for critical limb ischemia amputee patients, the WHOQOL-BREF has the benefit of taking patients' evaluation or satisfaction with functioning into consideration. ${ }^{14,27}$ Therefore, we argue that the WHOQOL-BREF is an appropriate instrument to measure QoL in critical limb ischemia amputee patients. In this study, QoL did not deteriorate after major limb amputation. Even more so, patients indicated they were significantly more satisfied with their physical QoL after amputation compared with before amputation.

Other questionnaires, such as the SF-36, lack discriminatory power in critical limb ischemia patients characterized by their many comorbidities. ${ }^{15,29,30}$ Since the SF-12 is an abbreviated version of the SF-36; our results of HS improvement, after major limb amputation, should be interpreted with care. Still, the scores on the physical and mental HS scale did not deteriorate after major limb amputation. These results are in line with the amputee placebo group of Peeters et al in their study investigating the effect on HS of bone marrow derived mononuclear cell administration in critical limb ischemia patients without treatment options. ${ }^{31}$

The prevalence of depression in PAD patients has a range between 3\% and 48\%. ${ }^{32}$ Arya et al and McDermott et al stated that depression in PAD patients leads to a significantly higher risk of mortality. ${ }^{16,33}$ Moreover, Arya et al described an increased amputation rate in PAD patients with symptoms of depression. ${ }^{16} \mathrm{~A}$ review on depression in amputees, from varying etiologies, concluded that depression rates are relatively high up to 2 years after major limb amputation. ${ }^{34}$ However, little is known about depression after major limb amputation due to critical limb ischemia in the elderly alone. ${ }^{35}$ Our study demonstrated that critical limb ischemia patients experienced less symptoms of depression after major limb amputation. A possible explanation for the decrease in scores of symptoms of depression can be the relief of ischemic rest pain in the limb after major limb amputation in the elderly critical limb ischemia patients. So, from a mood-disorder point of view, improved outcome is possible with major limb amputation. Therefore, screening for symptoms of 
depression is important to complement the shared-decision making process in elderly critical limb ischemia patients.

In patients undergoing major limb amputation, from any cause, mortality rates are extremely high. The 30-day mortality rates and the in-hospital mortality rates range between $4 \%$ and $22 \%{ }^{5}$ After 1 year, mortality rates in critical limb ischemia patients are even higher; up to $44 \%$ in patients aged 70 or older. ${ }^{7,36-39}$ Within 2 years' time, 1 in 2 patients will have deceased after major limb amputation. ${ }^{7,38,39}$ Our results are in line with these previously mentioned studies. The 30-day mortality rate was $16 \%$, one-year was $39 \%$ and two-year was $55 \%$. These high mortality rates raise the question of what outcome is more important to achieve after major limb amputation. Along this line, one should consider patients who may benefit from having an earlier major limb amputation. Shared-decision making concerning this topic is important, since each patient may value his/ her limb salvage differently.

Clearly, this study has limitations. First, the sample size of critical limb ischemia amputee patients decreases over time. Due to high mortality rates in this particular patient population, the sample size can be considered fairly large for a two-center study and also compared to other studies. However, attrition due to mortality could have biased our conclusions. Secondly, symptoms of depression were measured by self-report questionnaires. Self-report questionnaires are not yet part of standard care. The gold standard in diagnosing depression is the use of diagnostic interviews. ${ }^{40,41}$ However, if one wants to assess symptoms of depression quickly in routine care, the CES-D questionnaire is a frequently used and accurate instrument in elderly patients. ${ }^{42}$ Third, because there was no control group to compare the amputees to, any changes in QoL, HS and depression following amputation can be confounded by other factors not related to the intervention, such as spontaneous recovery.

\section{Conclusion}

Elderly critical limb ischemia amputee patients are a fragile population with high short and long-term mortality rates. In this study, we concluded that QoL and HS did not diminish after major limb amputation, neither in the shortterm or the long-term. Moreover, our results show that major limb amputation in the elderly critical limb ischemia patients in the long term gives an acceptable QoL, which, in some aspects, is comparable to the QoL of their peers. Individual treatment goal setting plays an important role when undergoing hospital care, especially in elderly patients. In order to accomplish a good shared-decision making process that does not delay the timing of major limb amputation, patients and family should not only be informed about the mortality rates but also about the fact that QoL and HS does not seem to diminish in critical limb ischemia amputees, aged 70 and older, in the long-term.

\section{Disclosure}

The authors report no conflicts of interest in this work.

\section{References}

1. Farber A, Eberhardt RT. The current state of critical limb ischemia a systematic review. JAMA Surg. 2016;151(11):1070-1077. doi:10.1001/jamasurg.2016.2018

2. Norgren L, Hiatt WR, Dormandy JA, Nehler MR, Harris KA, Fowkes FGR. Inter-society consensus for the management of peripheral arterial disease (TASC II). J Vasc Surg. 2007;45(1):5-67. doi:10.1016/j.jvs.2006.12.037

3. Becker F, Robert-Ebadi H, Ricco J-B, et al. Chapter I: definitions, epidemiology, clinical presentation and prognosis. Eur J Vasc Endovasc Surg. 2011;42(S3):S4-12. doi:10.1016/j.ejvs.2011.06.053

4. Reinecke H, Unrath M, Freisinger E, et al. Peripheral arterial disease and critical limb ischaemia: still poor outcomes and lack of guideline adherence. Eur Heart J. 2015;36:932-938. doi:10.1093/eurheartj/ehv006

5. Van Netten JJ, Fortington LV, Hinchliffe RJ, Hijmans JM. Early postoperative mortality after major lower limb amputation: a systematic review of population and regional based studies. Eur $J$ Vasc Endovasc Surg. 2016;51(2):248-258. doi:10.1016/j.ejvs.2015.10.001

6. Malyar NM, Freisinger E, Meyborg M, et al. Low rates of revascularization and high in-hospital mortality in patients with ischemic lower limb amputation: morbidity and mortality of ischemic amputation. Angiology. 2016;67(9):860-869. doi: $10.1177 / 0003319715626849$

7. Cruz CP, Eidt JF, Capps C, Kirtley L, Moursi MM. Major lower extremity amputations at a Veterans Affairs hospital. Am J Surg. 2003;186(5):449-454. doi:10.1016/j.amjsurg.2003.07.027

8. Norvell DC, Turner AP, Williams RM, Hakimi KN, Czerniecki JM. Defining successful mobility after lower extremity amputation for complications of peripheral vascular disease and diabetes. $J$ Vasc Surg. 2011;54(2):412-419. doi:10.1016/j.jvs.2011.01.046

9. Taylor SM, Kalbaugh CA, Cass AL, et al. "Successful outcome" after below-knee amputation: an objective definition and influence of clinical variables. Am Surg. 2008;74(7):607-613.

10. Hawkins AT, Henry AJ, Crandell DM, Nguyen LL. A systematic review of functional and quality of life assessment after major lower extremity amputation. Ann Vasc Surg. 2014;28(3):763-780. doi:10.1016/j.avsg.2013.07.011

11. Breek JC, De Vries J, Van Heck GL, Van Berge Henegouwen DP, Hamming JF. Assessment of disease impact in patients with intermittent claudication: discrepancy between health status and quality of life. J Vasc Surg. 2005;41(3):443-450. doi:10.1016/j.jvs.2004.12.042

12. O'Boyle CA. Assessment of quality of life in surgery. Br J Surg. 1992;79(5):395-398. doi:10.1002/bjs. 1800790506

13. Bradley C. Importance of differentiating health status from quality of life. Lancet. 2001;357:7-8. doi:10.1016/S0140-6736(00) $03562-5$

14. Hamming JF, de Vries J. Measuring quality of life. $\mathrm{Br} J$ Surg. 2007;94(8):923-924. doi:10.1002/(ISSN)1365-2168

15. Suckow BD, Goodney PP, Nolan BW, et al. Domains that determine quality of life in vascular amputees. Ann Vasc Surg. 2015;29(4):722730. doi:10.1016/j.avsg.2014.12.005 
16. Arya S, Lee S, Zahner GJ, et al. The association of comorbid depression with mortality and amputation in veterans with peripheral artery disease. J Vasc Surg. 2018;68:536-545.e2. doi:10.1016/j. jvs.2017.10.092

17. Steunenberg S, de Vries J, Raats JW, et al. Quality of life and mortality after endovascular, surgical or conservative treatment of elderly suffering from critical limb ischemia. Ann Vasc Surg. 2018;51:95-105. doi:10.1016/j.avsg.2018.02.044

18. WHO. The WHOQOL Group. Development of the World Health Organization WHOQOL-BREF quality of life assessment. Psychol Med. 1998;28(3):551-558. doi:10.1017/S0033291798006667

19. von Steinbüchel N, Lischetzke T, Gurny M, Eid M. Assessing quality of life in older people: psychometric properties of the WHOQOL-BREF. Eur $J$ Ageing. 2006;3(2):116-122. doi:10.1007/s10433-006-0024-2

20. Trompenaars FJ, Masthoff ED, van Heck GL, Hodiamont PP, de Vries J. Content validity, construct validity, and reliability of the WHOQOL-Bref in a population of Dutch adult psychiatric outpatients. Qual Life Res. 2005;14(1):151-160. doi:10.1007/s11136-004-0787-x

21. Shou J, Ren L, Wang H, et al. Reliability and validity of 12-item Short-Form health survey (SF-12) for the health status of Chinese community elderly population in Xujiahui district of Shanghai. Aging Clin Exp Res. 2016;28(2):339-346. doi:10.1007/s40520-015-0401-9

22. Ware JEJ, Kosinski M, Keller SD. A 12-item short-form health survey: construction of scales and preliminary tests of reliability and validity. Med Care. 2005;14(1):151-160.

23. Penn-Barwell JG. Outcomes in lower limb amputation following trauma: a systematic review and meta-analysis. Injury. 2011;42 (12):1474-1479. doi:10.1016/j.injury.2011.07.005

24. Radloff LS. The CES-D scale: a self-report depression scale for research in the general population. Appl Psychol Meas. 1977;1:385401. doi:10.1177/014662167700100306

25. Irwin M, Artin KH, Oxman MN. Screening for Depression in the older adult: criterion validity of the 10-item Center for Epidemiological Studies Depression Scale (CES-D). Arch Intern Med. 1999;159(15):1701-1704. doi:10.1001/archinte.159.15.1701

26. Schroevers MJ, Sanderman R, Van Sonderen E, Ranchor AV. The evaluation of the Center for Epidemiologic Studies Depression (CESD) scale: depressed and positive affect in cancer patients and healthy reference subjects. Qual Life Res. 2000;9(9):1015-1029. doi:10.1023/ A: 1016673003237

27. de Vries J. Beyond health status: Construction and validation of the Dutch WHO Quality of Life assessment instrument [Ph.D. thesis]. Tilburg: Tilburg University; 1996.

28. Shammas NW. Epidemiology, classification, and modifiable risk factors of peripheral arterial disease. Vasc Health Risk Manag. 2007;3 (2):229-234. doi:10.2147/vhrm.2007.3.2.229

29. de Vries M, Ouwendijk R, Kessels AG, et al. Comparison of generic and disease-specific questionnaires for the assessment of quality of life in patients with peripheral arterial disease. J Vasc Surg. 2005;41 (2):261-268. doi:10.1016/j.jvs.2004.11.022
30. Chetter IC, Spark JI, Scott DJA, Kent PJ, Berridge DC, Kester RC. Prospective analysis of quality of life in patients following infrainguinal reconstruction for chronic critical ischaemia. $\mathrm{Br} J$ Surg. 1998;85:951-955. doi:10.1046/j.1365-2168.1998.00752.x

31. Peeters Weem SMO, Teraa M, Den Ruijter HM, De Borst GJ, Verhaar MC, Moll FL. Quality of life after treatment with autologous bone marrow derived cells in no option severe limb ischemia. Eur $J$ Vasc Endovasc Surg. 2016;51(1):83-89. doi:10.1016/j. ejvs.2015.09.010

32. Brostow DP, Petrik ML, Starosta AJ, Waldo SW. Depression in patients with peripheral arterial disease: a systematic review. Eur J Cardiovasc Nurs. 2017;147451511668722. doi:10.1177/ 1474515116687222

33. McDermott MM, Guralnik JM, Tian L, et al. Incidence and prognostic significance of depressive symptoms in peripheral artery disease. $J$ Am Heart Assoc. 2016;5(3):e002959. doi:10.1161/JAHA.115.002959

34. Horgan O, MacLachlan M. Psychosocial adjustment to lower-limb amputation: a review. Disabil Rehabil. 2004;26(14-15):837-850. doi:10.1080/09638280410001708869

35. Caplan LM, Hackett TP. Emotional effects of lower-limb amputation in the aged. $N$ Engl J Med. 1963;269(22):1166-1171. doi:10.1056/ NEJM196311282692203

36. Klaphake S, de Leur K, Mulder PGH, et al. Mortality after major amputation in elderly patients with critical limb ischemia. Clin Interv Aging. 2017;12:1985-1992. doi:10.2147/CIA.S137570

37. Fortington LV, Geertzen JHB, Van Netten JJ, Postema K, Rommers GM, Dijkstra PU. Short and long term mortality rates after a lower limb amputation. Eur J Vasc Endovasc Surg. 2013;46(1):124-131. doi:10.1016/j.ejvs.2013.03.024

38. Dormandy JA. Natural history of patients with peripheral occlusive arterial disease. Ann Chir Gynaecol. 1992;81(2):86-88.

39. Faglia E, Clerici G, Gabrielli L, et al. Long-term prognosis of diabetic patients with critical limb ischemia: a population-based cohort study. Diabetes Care. 2009;32(5):822-827. doi:10.2337/ dc08-1223

40. First MB, Williams JBW, Karg RS, Spitzer RL. Structured Clinical Interview for DSM-5-Clinical Version (SCID-5 for DSM- 5, Clinical Version; SCID-5-CV, Version 1.0.0). Arlington, VA: American Psychiatric Association; 2015

41. Krebber AM, Buffart LM, Kleijn G, et al. Prevalence of depression in cancer patients: a meta-analysis of diagnostic interviews and selfreport instruments. Psychooncology. 2014;23(2):121-130. doi:10.1002/pon.3409

42. Cheng S-T, Chan ACM. The Center for Epidemiologic Studies Depression Scale in older Chinese: thresholds for long and short forms. Int $J$ Geriatr Psychiatry. 2005;20(5):465-470. doi:10.1002/ gps. 1314
Clinical Interventions in Aging

\section{Publish your work in this journal}

Clinical Interventions in Aging is an international, peer-reviewed journal focusing on evidence-based reports on the value or lack thereof of treatments intended to prevent or delay the onset of maladaptive correlates of aging in human beings. This journal is indexed on PubMed Central, MedLine, CAS, Scopus and the Elsevier
Dovepress

Bibliographic databases. The manuscript management system is completely online and includes a very quick and fair peer-review system, which is all easy to use. Visit http://www.dovepress.com/ testimonials.php to read real quotes from published authors. 